\title{
VOLTAMMETRIC CHARACTERIZATION OF THE IRON BEHAVIOUR FROM STEELS IN DIFFERENT ELECTROLYTIC MEDIA
}

\author{
Gheorghe Nemtoi ${ }^{*}$, Florica Ionica ${ }^{2}$, Tudor Lupascu ${ }^{3}$ and Alexandru Cecal ${ }^{1}$ \\ 1 “Al.I.Cuza” University, Faculty of Chemistry, 11-Carol I Brd., 700506 - Iasi, Romania \\ 2 "Petru Rares" National College, 4 Stefan cel Mare str., 610101, Piatra-Neamt, Romania \\ ${ }^{3}$ Institute of Chemistry, Moldavian Academy of Science, Republic of Moldova \\ *Email:nemtoi@uaic.ro
}

\begin{abstract}
The dissolution of the iron from steel was observed by drawing the cyclic voltammetry (CV) for the systems consisting of the solution resulted when the alloy sample was immersed in $\mathrm{HNO}_{3}, \mathrm{H}_{2} \mathrm{SO}_{4}$, and $\mathrm{HCl}$, aqueous solutions on platinum disk electrode (PtDE). The presence of some redox processes can be observed only in $\mathrm{HNO}_{3}$ which confirms the complexity of the mechanism of Fe dissolution in this acid. On the other hand, there were manufactured electrodes of steel samples taken into experiment achieving the corrosion characteristics in the media mentioned above.
\end{abstract}

Keywords: corrosion, cyclic voltammetry, peak potential, polarization curves, steel.

\section{Introduction}

In the characterization of the behaviour of metals and alloys, a main role belongs to the electrochemical approaches, and among them the voltammetry is frequently used [1-4].

The necessity of these studies appeared due to the frequent practical implications such as the electrolytic extraction and treating of metals, the change of the metal surfaces through deposit or electrochemical polishing and electroplating, corrosion, current electrochemical sources, electrochemical syntheses, sensors.

Within the electrochemical corrosion of metals, which is in fact an anodic dissolution, free metal ions or insoluble products can be appeared, which are characteristic to the passive state [5]. Generally these processes imply the interaction between the surface of the metal and that of the electrolyte, the transfer of the electrons, the electrochemical reaction, and the diffusion of the ions or the molecules. For a more accurate comprehension of the mechanisms of anodic dissolution it is necessary to know the state of the surface of the metal, the chemistry of the interface solid-liquid and of the electrochemical processes [6].

The anodic dissolution processes led to relatively small electric potentials, in which the determinant step rate is the charge transfer or concomitantly the charge transfer and diffusion, results in kinetic rate and mix respectively [7-8]. The behaviour of metals in different electrolytic mediums can be estimated by the help of Pourbaix diagrams [9].

The significance of these diagrams is limited because it refers to ideal electrolyte solutions, to pure metal and not to alloys. These diagrams do not take into consideration the nature of the acid or of the base which modify $\mathrm{pH}$ value. It does not modify the risk of the cathode corrosion in immunity either, where the potential is strongly electronegative and the drawing of the diagram is based on the thermodynamic data, without taking into consideration the kinetic calculations [10].

\section{Experimental}

\section{Electrodes and electrolytes}

In Table 1 the composition of the five alloy samples, which followed two ways of study is given:

a) the steel dissolution in $\mathrm{H}_{2} \mathrm{SO}_{4}, \mathrm{HCl}$ and $\mathrm{HNO}_{3}$ aqueous solutions as well as in $\mathrm{NaOH}$ alkaline solution and the drawing of the cyclic voltammogram (CV), using as a work electrode (WE) an platinum disk electrode (PtDE), 2mm in diameter, an auxiliary electrode (AE) - a Pt wire $1 \mathrm{~mm}$ in diameter and 10mm long, and as reference electrode (RE) the saturated calomel electrode (SCE);

b) the constitution of work electrodes from each of the alloy samples and their coupling with AE of Pt and the reference electrode SCE for the voltammetric studies.

Table 1

The composition of the alloy samples considered in the study

\begin{tabular}{|c|c|c|c|c|c|c|c|c|c|c|c|}
\hline Sample & $\mathrm{Fe}$ & $\mathrm{C}$ & $\mathrm{Mn}$ & $\mathrm{Si}$ & $\mathrm{Cu}$ & $\mathrm{Sn}$ & $\mathrm{Ni}$ & $\mathrm{Mo}$ & $\mathrm{Cr}$ & $\mathrm{Pb}$ & $<0.1 \%$ \\
\hline 1 & 98.10 & 0.13 & 0.71 & 0.35 & - & - & - & 0.07 & 0.09 & 0.110 & $\mathrm{~S}, \mathrm{~B}, \mathrm{Zn}, \mathrm{Pb}, \mathrm{V}, \mathrm{Al}$ \\
\hline 2 & 98.00 & 0.23 & 0.84 & 0.24 & 0.11 & 0.083 & 0.05 & 0.02 & 0.13 & 0.090 & $\mathrm{~S}, \mathrm{Sb}, \mathrm{Nb}, \mathrm{Al}, \mathrm{Ti}$ \\
\hline 3 & 98.90 & 0.11 & 0.33 & 0.02 & 0.12 & 0.160 & 0.08 & 0.02 & 0.10 & 0.090 & $\mathrm{~S}, \mathrm{Nb}, \mathrm{V}, \mathrm{Ti}$ \\
\hline 4 & 97.30 & 0.23 & - & 0.25 & - & - & 0.24 & 0.16 & 0.63 & 0.009 & $\mathrm{~S}, \mathrm{~B}, \mathrm{As}, \mathrm{Ti}$ \\
\hline 5 & 98.10 & 0.20 & 0.66 & 0.24 & 0.30 & 0.146 & 0.10 & 0.02 & 0.06 & 0.010 & $\mathrm{~S}, \mathrm{Nb}, \mathrm{Al}$ \\
\hline
\end{tabular}


For the determination of some parameters characteristic to Fe corrosion, out of each alloy sample there were made disk-shaped work electrodes with $\Phi=5 \mathrm{~mm}$, introduced in a polymeric matrixt. As a reference electrode the saturated calomel electrode (SCE) was used and Pt plan electrode $(1 \mathrm{x} 1 \mathrm{~cm})$ as an auxiliary electrode was employed.

The solutions used as electrolytic media were prepared of highly pure analytic substances and the bidistillated water, and, before the drawing of the voltammogram, the oxygen was eliminated through bubbling with nitrogen for 10 minutes.

\section{The equipment and the working manner}

For the drawing of the polarization diagrams of the systems studied in a), there was used the electrochemical device VoltaLab 32 (Radiometer Copenhagen), which has among its components a DEA-332 Potentiostat (Digital Electrochemical Analyzer), an electrochemical cell with the three electrodes mentioned above, which is equipped with a thermostating matrix, a nitrogen bubbling system for the elimination of the oxygen dissolved in the solution, a data interface IMT 102, connected to a computer with Volta Master 2 software.

At certain moments from the immersion, out of the solutions in which the alloy sample was introduced there were taken volumes of $1 \mathrm{~mL}$ each in the electrochemical cell and there were diluted with bidistillated water at $30 \mathrm{~mL}$ for the drawing of the CV. Regarding the considered system, there were drawn CV on domain $1000 \div-100 \mathrm{mV}$ (on domain $-100 \div 1000 \mathrm{mV}$ a much higher initial cathode current was found, due to the formation of hydrogen, reason for which it was chosen this order of sweeping the potential), at $100 \mathrm{mV} / \mathrm{s}$.

For the studies in b) before each series of determination, WE was grinded with emery of different granulosities (from 200 to $2000 \mathrm{msh}$ ), ungreased and cleaned with bidistillated water. The voltammetric behaviour of WE prepared in this way was studied using the Potentiostat PG STAT 302N Autolab (Netherlands - Eco Chemie), which has among its components GPES software for taking and processing the findings.

\section{Results and discussions}

The experimental data relieved the fact that at the anodic dissolution of Fe an important role belongs to the water molecules and to the anions adsorbed on the surface. The following simplified mechanism was suggested [11]:

$$
\begin{aligned}
& \mathrm{Fe}+\mathrm{H}_{2} \mathrm{O} \rightarrow \mathrm{Fe}(\mathrm{OH})_{a d s}+\mathrm{H}^{+}+e^{-} \\
& \mathrm{Fe}(\mathrm{OH})_{a d s} \rightarrow \mathrm{FeOH}{ }^{+}+e^{-} \\
& \mathrm{FeOH}^{+} \rightarrow \mathrm{Fe}^{2+}+\mathrm{HO}^{-}
\end{aligned}
$$

and the presence of chloride anion will generate the following processes:

$$
\begin{aligned}
& \mathrm{Fe}+\mathrm{Cl}^{-} \rightarrow \mathrm{FeCl}_{a d s}+1 e \\
& \mathrm{FeCl}_{\text {ads }} \rightarrow \mathrm{FeCl}^{+}+1 e \\
& \mathrm{FeCl}^{+} \rightarrow \mathrm{Fe}^{2+}+1 e
\end{aligned}
$$

The mechanism of the hydroxide implies as intermediates adsorbed hydroxyl ions, which catalyzes the iron dissolution to produce hydrated ferrous hydroxide. This kind of mechanism, which implies the adsorbed hydroxyl ion, leads to the passivity of metals through the increase of the anodic polarization.

In the presence of the chloride ion, which is also active on the surface of the electrode, there is a competition between the adsorption of the chloride ion and hydroxyl respectively. In the case of the mechanism suggested for the chloride ion there will not take place the passivity of iron, this one preventing the formation of the oxide layer on the surface of iron. There were proposed two mechanisms for the formation of iron oxide layer on the surface of iron.

$\mathrm{Fe}(\mathrm{OH})_{2}$ can also formed during these processes based the electrocoagulation approach when the insoluble iron(II) hydroxides keeps away the pollutants as some possible complex compounds or through the electrostatics attraction [12].

The anodic dissolution of pure iron constituted the task of many studies regarding the corrosion phenomenon, concluded through the treatments given by Bockris and Koch [13]. They do not assert that the stage of the dissolution of the iron either in pure iron or in alloys would be the main stage of the anodic process which takes place in the iron dissolution. A minute presentation of the mechanism of the anodic iron dissolution was presented by Despic and co. [14].

In Fig. 1 - 3, is shown CV diagram obtained for the solution resulted from the total dissolution of sample 1 in $\mathrm{HNO}_{3}-4 \mathrm{M}$, in which there appear a cathode peak and two anodic peaks. 


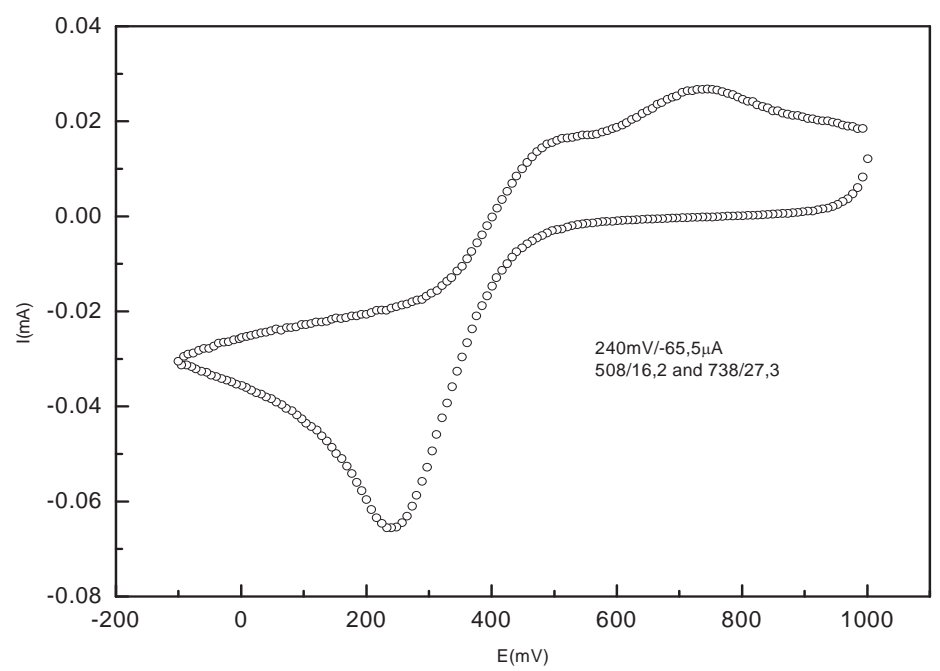

Fig. 1. CV obtained for the solution resulted from the total dissolution of sample 1 in $\mathrm{HNO}_{3}-4 \mathrm{M}$.

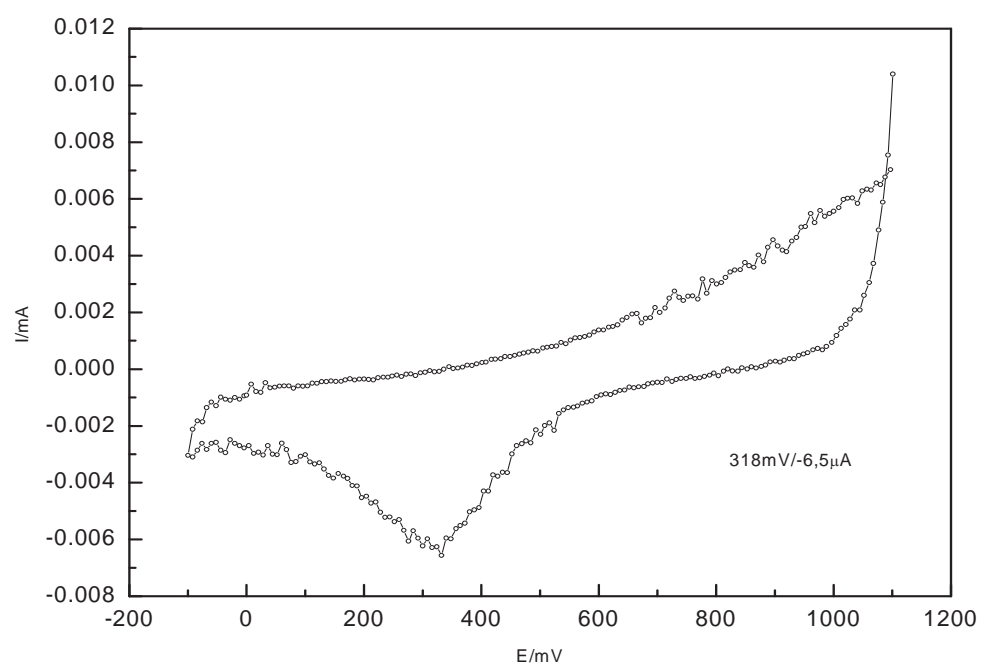

Fig. 2. $\mathrm{CV}$ of $\mathrm{HNO}_{3}-4 \mathrm{M}$ on EDPt, $100 \mathrm{mV} / \mathrm{s}$.

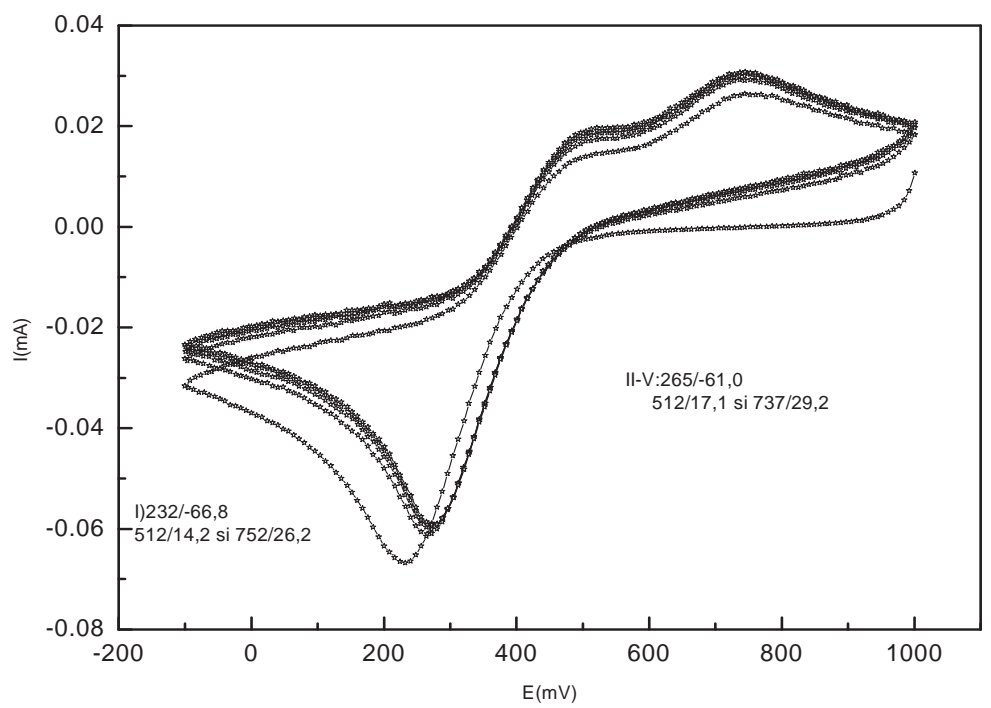

Fig. 3. $\mathrm{CV}$ of multiple cycling ( $\mathrm{n}=5)$ for the dissolution of sample 1 in $\mathrm{HNO}_{3} 4 \mathrm{M}$. 
Comparing with the CV curves drawn under the same conditions only for the solution $\mathrm{HNO}_{3} 4 \mathrm{M}$, presented in Fig. 2, there can be observed that the cathode peak is much smaller and shifted to the right side, while no other anodic peaks appear. In Fig. 3 the $\mathrm{CV}$ curves obtained for the sample 1 in $\mathrm{HNO}_{3} 4 \mathrm{M}$, under the conditions of multiple cycling, in which there can be noticed a slight shift of the diagram in the first cycle of sweep, in the following ones the difference between the plats being very small, a proof that the reduction - oxidation process can be considered quasi - reversible.

The reduction peak corresponds to $\mathrm{NO}_{3}{ }^{-}$and to the existing species in the solution at the iron dissolution, considering the modification within time of the cathode peak intensity, for sample 4 in $\mathrm{HNO}_{3} 4 \mathrm{M}$ and in $\mathrm{HNO}_{3} 2 \mathrm{M}_{\text {, }}$ determining the following dependence:

a) in $\mathrm{HNO}_{3} 4 \mathrm{M}$ solution:

$\mathrm{I}(\mu \mathrm{A})=34,44-3,83 \mathrm{t}+4,4 \cdot 10^{-2} \mathrm{t}^{2}-1,577 \cdot 10^{-4} \mathrm{t}^{3}$

corellation coefficient $\mathrm{R}=0.98355$

b) in $\mathrm{HNO}_{3} 2 \mathrm{M}$ solution:

$\mathrm{I}(\mu \mathrm{A})=-4,78+2,08 \cdot 10^{-2} \mathrm{t}-1,98 \cdot 10^{-3} \mathrm{t}^{2}$

corellation coefficient $\mathrm{R}=0.995$, where $\mathrm{t}$ is the time in minutes.

The dissolution of the alloy samples took place in $\mathrm{HNO}_{3}$ solution of $(0.25 \div 4 \mathrm{M})$ concentration, the drawing of $\mathrm{CV}$ achieving with the dilution of each concentrations from which the alloy dissolved, in Table 2 being presented the characteristics of the reduction peak to five concentrations in the absence of the alloy. There can be noticed that the peak intensity does not depend on the concentration of the acid, and the modification of the peak potential can be attributed to the adsorption processes which take place on PtDE.

The peak characteristic in $\mathrm{HNO}_{3}$ solutions of different concentrations

Table 2

\begin{tabular}{|c|c|c|c|c|c|}
\hline $\begin{array}{c}\mathbf{H N O}_{3}(\mathrm{~mol} / \mathrm{L}) \\
\text { concentration }\end{array}$ & $\mathbf{0 . 1 3 6}$ & $\mathbf{0 . 0 6 7}$ & $\mathbf{0 . 0 3 3}$ & $\mathbf{0 . 0 1 6}$ & $\mathbf{0 . 0 0 8}$ \\
\hline $\mathrm{E}_{\mathrm{C}}(\mathrm{mV})$ & 364 & 252 & 318 & 300 & 316 \\
\hline$-\mathrm{I}_{\mathrm{C}}(\mu \mathrm{A})$ & 5.52 & 7.62 & 6.5 & 6.67 & 7.16 \\
\hline
\end{tabular}

Irrespective of the concentration of the acid in the samples, there was obtained no anodic peaks in CV, what proves that the reduction of nitrogen group is an irreversible process in the conditions of CV drawing.

The drawing of $\mathrm{CVs}$ for $\mathrm{HNO}_{3}$ solutions which contain dissolved Fe lead to two anodic peaks, and the intensity of the cathode peak is higher, which proves that beside the reduction of $\mathrm{NO}_{3}^{-}$group there are also electrochemical species, which resulted at the iron dissolution and reduce within the same domain.

The formation of water in the neighbouring of the electrode accelerates the reaction of the iron dissolution and the current becomes higher than the current of limit diffusion; Fe(II) $)_{\text {sol }}$ so formed is the promoter of the reaction of the reduction of $\left(\mathrm{NO}_{2}\right)_{\text {ads }}$. Based on the data presented above, there concludes that the mechanism of the dissolution of Fe in aqueous solution of nitric acid is complex, and the voltammetric approach allows to make only a series of qualitative statements.

On $0.25 \div 4.00 \mathrm{M}$ concentration domain there were dissolved alloy samples in $\mathrm{H}_{2} \mathrm{SO}_{4}, \mathrm{HCl}$ or $\mathrm{NaOH}$ aqueous solutions, but CVs drawn gave no signs, the same thing being observed also for the alloy samples dissolved in much diluted $\mathrm{HNO}_{3}\left(10^{-5} \mathrm{M}\right)$ solutions.

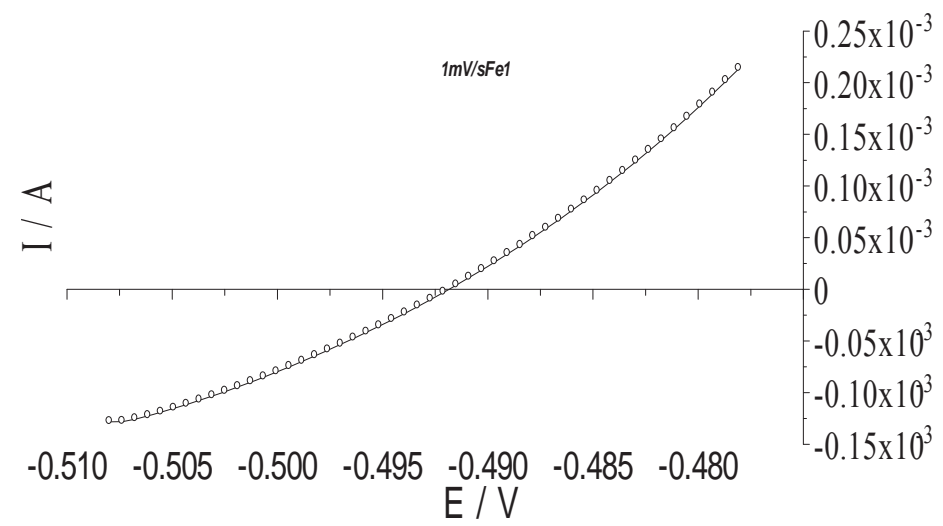

Fig. 4. The polarization diagram for the calculation of $R_{p}$ in $4 \mathrm{M} \mathrm{H}_{2} \mathrm{SO}_{4}$ of sample 1. 


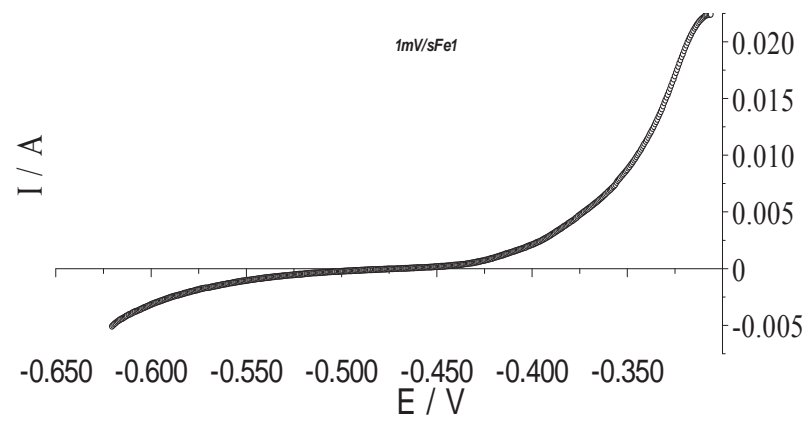

Fig. 5. The diagram of the polarization for the determination of Tafel parameters in $4 \mathrm{M} \mathrm{H}_{2} \mathrm{SO}_{4}$, sample 1 .

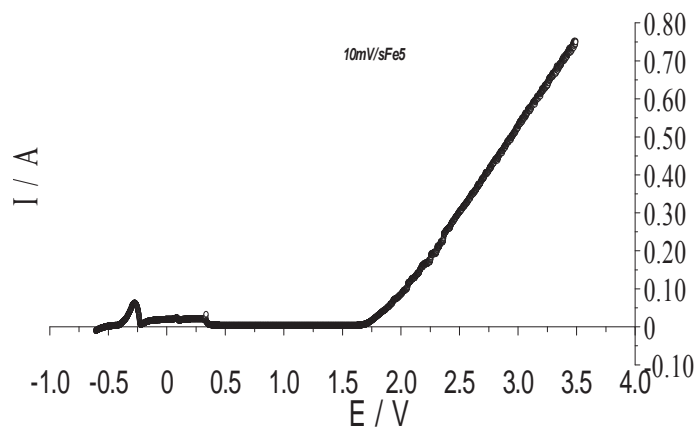

a)

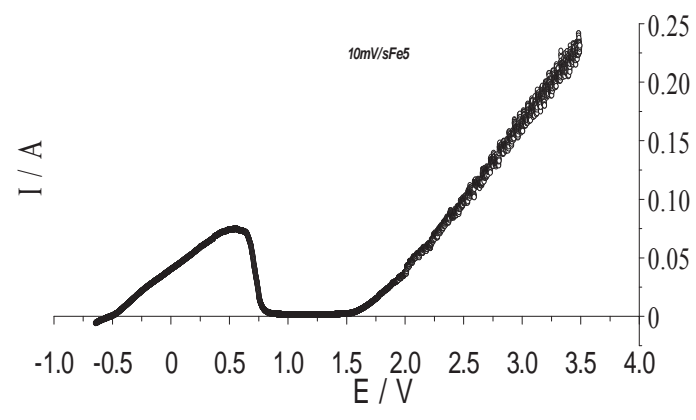

b)

Fig. 6. The diagrams of polarization of sample 5 in $\mathrm{H}_{2} \mathrm{SO}_{4} 4 \mathrm{M}$ (a) and in $\mathrm{H}_{2} \mathrm{SO}_{4} 0.25 \mathrm{M}(\mathrm{b})$.

Following the latter direction of the study (b), the evaluation of the corrosion phenomenon was achieved by the polarizing resistance approach, by the measurement of the current in the corrosion potential domain, as it is presented in Fig. 4, and the slope at the corrosion potential will be:

$$
\frac{1}{R_{p}}=\left(\frac{d I}{d E}\right)
$$

$\mathrm{R}_{\mathrm{p}}$ being the polarization resistance, the sweep rate of the giving potential $1 \mathrm{mV} / \mathrm{s}$, and the sweep domain very narrow $( \pm 15 \mathrm{mV}$ regarding the corrosion potential).

The polarization resistance can be calculated with Stern-Geary relation [15-16]:

$$
R_{p}=\frac{b_{a}\left|b_{c}\right|}{2,303 I_{\text {cor }}\left(b_{a}+\left|b_{c}\right|\right)}
$$

where $b_{a}$ and $b_{c}$ are the slopes of Tafel line, which will be obtained through the drawing of the voltammogram on an anodic and cathode domain compared to $150 \mathrm{mV}$ corrosion potential, as it is presented in Fig. 5, on the base of which $E=f(\log j)$ semi-logarithm representation leads to the obtaining of $b_{a}$ and $b_{c}[17-18]$.

To characterize the rate of the dissolution process of the iron in the steel, taken in the experiment the rate of the puncture defined by the equation was calculated:

where:

$$
V_{\text {cor }}=\frac{\delta}{t}=\frac{M}{z F \rho} j_{c o r}
$$

$\delta \quad-$ the thickness dissolved in the analyzed sample;

$\mathrm{T} \quad$ - time;

$\mathrm{M} / \mathrm{z} \quad$ - the equivalent molar mass (considered $\mathrm{z}=2$ );

F $\quad$ - Faraday constant $(96485 \mathrm{C} / \mathrm{mol})$;

$\rho \quad-$ the density of the analyzed sample;

$\mathrm{j}_{\text {cor }}-$ the corrosion current density. 
Out of the diagrams of polarization a first image of the behaviour of the alloy at corrosion in a medium given under well précised conditions can be taken out. The potentiodynamic plats are obtained through the continuous polarization of WE at a certain sweep rate of the potential with the recording of the value of the current. With these plates it may be obtained the most important parameters of the corrosion process: the critic polarization potential $\left(\mathrm{E}_{\mathrm{pc}}\right)$, the potential of passivity or Flade potential $\left(\mathrm{E}_{\mathrm{F}}\right)$, the break potential $\left(\mathrm{E}_{\mathrm{str}}\right)$ with corresponding values of the current as well as the possibility of establishing the domains: active $\left(\mathrm{D}_{\text {active }}\right)$, pre-passive $\left(\mathrm{D}_{\text {pre-passive }}\right)$, passive $\left(\mathrm{D}_{\text {passive }}\right)$.

Fig. 6 presents the polarization diagram on an extended potential range $(-0.6 \div 3.5 \mathrm{~V})$ for sample 5 in $\mathrm{H}_{2} \mathrm{SO}_{4} 4 \mathrm{M}$ (a) and $0.25 \mathrm{M}(\mathrm{b})$, obtaining in the case of concentrate $\mathrm{H}_{2} \mathrm{SO}_{4}$ solution also a pre-passive domain while in the diluted solution $\mathrm{E}_{\mathrm{pc}}$ (critic polarization potential) it is much shifted towards the right side (at positive values of the potential) and no pre-passive domain appears. Similar diagrams were also obtained for the other alloy samples, the results being presented in Table 3.

Table 3

The characteristics of the polarization curves of the iron alloys in different electrolytic mediums

\begin{tabular}{|c|c|c|c|c|c|c|c|c|}
\hline \multicolumn{9}{|c|}{ a) $\mathrm{H}_{2} \mathrm{SO}_{4} 4 \mathrm{M}$} \\
\hline $\begin{array}{c}\text { No. } \\
\text { sample }\end{array}$ & $\begin{array}{l}-E_{\text {cor }} \\
\text { (V) }\end{array}$ & $\begin{array}{l}+E_{p c} \\
(V)\end{array}$ & $\begin{array}{l}I_{p c} \\
(\mathrm{~A})\end{array}$ & $\begin{array}{l}E_{F} \\
(V)\end{array}$ & $\begin{array}{l}\mathbf{E}_{\text {Str }} \\
\text { (V) }\end{array}$ & $\begin{array}{l}D_{\text {activ }} \\
\text { (V) }\end{array}$ & $\begin{array}{c}\mathbf{D}_{\text {prepasiv }} \\
\text { (V) }\end{array}$ & $\begin{array}{c}\mathbf{D}_{\text {pasiv }} \\
\text { (V) }\end{array}$ \\
\hline 1 & 0.454 & -0.243 & $5.478 \cdot 10^{-2}$ & -0.204 & 1.696 & $-0.454 \div-0.247$ & $-214 \div 0.347$ & $0.347 \div 1.696$ \\
\hline 2 & 0.453 & -0.256 & $5.91 \cdot 10^{-2}$ & -0.209 & 1.675 & $-0.453 \div-0.256$ & $-0.256 \div 0.341$ & $0.341 \div 1.675$ \\
\hline 3 & 0.450 & -0.224 & $4.61 \cdot 10^{-2}$ & -0.189 & 1.664 & $-0.450 \div-0.224$ & $-0.189 \div 0.333$ & $0.362 \div 1.664$ \\
\hline 4 & 0.426 & -0.259 & $4.96 \cdot 10^{-2}$ & -0.206 & 1.685 & $-0.426 \div-0.259$ & $-0.206 \div 0.337$ & $0.368 \div 1.685$ \\
\hline 5 & 0.431 & -0.266 & $5.82 \cdot 10^{-2}$ & -0.220 & 1.698 & $-0.431 \div-0.220$ & $-0.220 \div 0.339$ & $0.379 \div 1.698$ \\
\hline \multicolumn{9}{|c|}{ b) $\mathrm{H}_{2} \mathrm{SO}_{4} 0.25 \mathrm{M}$} \\
\hline 1 & 0.510 & 0.711 & $6.9 \cdot 10^{-2}$ & 0.905 & 1.532 & $-0.510 \div-0.711$ & - & $0.905 \div 1.532$ \\
\hline 2 & 0.503 & 0.643 & $7.06 \cdot 10^{-2}$ & 0.870 & 1.534 & $-0.503 \div-0.643$ & - & $0.870 \div 1.534$ \\
\hline 3 & 0.462 & 0.541 & $5.44 \cdot 10^{-2}$ & 0.862 & 1.503 & $-0.462 \div-0.541$ & - & $0.862 \div 1.503$ \\
\hline 4 & 0.462 & 0.540 & $5.44 \cdot 10^{-2}$ & 0.808 & 1.535 & $-0.462 \div-0.540$ & - & $0.808 \div 1.535$ \\
\hline 5 & 0.485 & 0.566 & $7.37 \cdot 10^{-2}$ & 0.819 & 1.536 & $-0.485 \div-0.566$ & - & $0.819 \div 1.536$ \\
\hline \multicolumn{9}{|c|}{ c) $\mathrm{HCl} 4 \mathrm{M}$} \\
\hline 3 & 0.482 & 0.132 & $1.88 \cdot 10^{-1}$ & 0.236 & 1.934 & $-0.482 \div 0.132$ & - & $0.236 \div 1.934$ \\
\hline \multicolumn{9}{|c|}{ d) $\mathrm{HCl} 0.1 \mathrm{M}$} \\
\hline 3 & 0.505 & - & - & - & - & $-0.505 \div 2.869$ & - & - \\
\hline \multicolumn{9}{|c|}{ e) $\mathrm{HNO}_{3} 4 \mathrm{M}$} \\
\hline 5 & 0.280 & 0.452 & $4.91 \cdot 10^{-2}$ & 0.870 & 1.691 & $-0.280 \div 0.452$ & - & $0.870 \div 1.691$ \\
\hline \multicolumn{9}{|c|}{ f) $\mathrm{HNO}_{3} 0.1 \mathrm{M}$} \\
\hline 5 & 0.492 & 1.757 & $3.58 \cdot 10^{-2}$ & 1.846 & 1.915 & $-0.492 \div 1.757$ & - & $1.846 \div 1.915$ \\
\hline
\end{tabular}

The data in Table 3 point out a slight shift of $\mathrm{E}_{\text {cor }}$ of iron towards negative values in $\mathrm{H}_{2} \mathrm{SO}_{4}$ solution, $\mathrm{E}_{\mathrm{pc}}$ for diluted solutions shifts at positive values regarding the concentrated solution with almost $1.00 \mathrm{~V}$, while the intensity corresponding to each alloy sample is higher in the diluted solution. For diluted solutions, $\mathrm{E}_{\mathrm{F}}$ shifts to positive values with more than $1.00 \mathrm{~V}$, too. The trans-passivity of the sample in the diluted solution appears earlier than in the concentrated solution $\left(\mathrm{E}_{\mathrm{str} .4 \mathrm{M}}<\mathrm{E}_{\text {str.0.25M }}\right)$. The active domain of the corrosion of the samples is strongly diminished in the concentrated solution as compared to the diluted one, in which the pre-passive domain does not appear any longer as in the case of the concentrated $\mathrm{H}_{2} \mathrm{SO}_{4}$ solutions. The passive domain of the alloy samples is larger in the concentrated solution than in the diluted one [19-21]. The data obtained from the analysis of the polarization diagrams confirm that the five Fe alloy samples are very close not only from the composition point of view but also from the structural one, and the different additions do not lead to different voltammetric behaviour.

Since the behaviour of the five samples in $\mathrm{HCl}, \mathrm{H}_{2} \mathrm{SO}_{4}$, and $\mathrm{NaOH}$ aqueous solutions media is characterized by very close values of the parameters of the polarization plat, in Table 3 are given the parameters obtained for a single sample. 
The parameters of the corrosion of iron in alloys in different electrolytic mediums $4.00 \mathrm{M} \mathrm{H}_{2} \mathrm{SO}_{4}$

\begin{tabular}{|c|c|c|c|c|c|c|c|}
\hline \multirow{3}{*}{$\begin{array}{c}\text { No. } \\
\text { sample }\end{array}$} & \multirow{3}{*}{$\begin{array}{c}\mathrm{R}_{\mathrm{p}} \\
\Omega\end{array}$} & \multirow{3}{*}{$\begin{array}{l}10^{3} \mathrm{j}_{\text {cor }} \\
\mathrm{A} / \mathrm{cm}^{2}\end{array}$} & \multicolumn{2}{|c|}{ Tafel } & \multirow{3}{*}{$\begin{array}{c}\mathrm{R}_{\mathrm{p}} \\
\text { (Tafel) }\end{array}$} & \multirow{3}{*}{$\begin{array}{c}\overline{R_{p}} \\
\Omega\end{array}$} & \multirow{3}{*}{$\begin{array}{c}\mathrm{v}_{\text {cor }} \\
\mathrm{mm} / \text { year }\end{array}$} \\
\hline & & & $\left|b_{c}\right|$ & $\mathrm{b}_{\mathrm{a}}$ & & & \\
\hline & & & \multicolumn{2}{|c|}{$\mathrm{V}$} & & & \\
\hline 1 & 22.4 & 1.629 & 0.095 & 0.079 & 15.5 & 20.45 & 19.80 \\
\hline 2 & 38.2 & 1.524 & 0.101 & 0.088 & 16.7 & 27.45 & 16.67 \\
\hline 3 & 29.1 & 1.076 & 0.092 & 0.032 & 46.3 & 37.70 & 15.6 \\
\hline 4 & 62.3 & 0.896 & 0.104 & 0.041 & 51.5 & 56.90 & 11.01 \\
\hline 5 & 78.2 & 0.142 & 0.071 & 0.106 & 59.6 & 68.9 & 9.17 \\
\hline \multicolumn{8}{|c|}{$0.25 \mathrm{M} \mathrm{H}_{2} \mathrm{SO}_{4}$} \\
\hline 1 & 82.8 & 1.989 & 0.143 & 0.081 & 80.9 & 81.7 & 0.989 \\
\hline 2 & 28.1 & 3.751 & 0.136 & 0.159 & 24.2 & 26.15 & 3.839 \\
\hline 3 & 17.1 & 0.150 & 0.118 & 0.024 & 16.3 & 16.7 & 0.154 \\
\hline 4 & 16.7 & 4.750 & 0.156 & 0.186 & 13.5 & 15.1 & 4.864 \\
\hline 5 & 28.7 & 0.963 & 0.150 & 0.151 & 19.6 & 24.15 & 2.036 \\
\hline \multicolumn{8}{|c|}{$\mathrm{HCl} 0.25 \mathrm{M}$} \\
\hline 2 & 91.16 & 0.197 & 0.240 & 0.046 & 24.55 & 57.85 & 10.27 \\
\hline \multicolumn{8}{|c|}{$\mathrm{HCl} 4 \mathrm{M}$} \\
\hline 3 & 315.9 & 0.22 & 0.104 & 0.102 & 106.8 & 211.35 & 2.263 \\
\hline \multicolumn{8}{|c|}{$\mathrm{HNO}_{3} 4 \mathrm{M}$} \\
\hline 4 & 2.78 & 48.81 & 0.131 & 0.257 & 1.54 & 2.16 & 49.9 \\
\hline 5 & 1.72 & 76.78 & 0.162 & 0.208 & 0.97 & 1.34 & 89.6 \\
\hline
\end{tabular}

In the case of the diluted $\mathrm{HCl}(0.1 \mathrm{M})$ solution, the corrosion is continuous distinguished but no passive or prepassive domain can be deduced. The nitric acid solution, both diluted and concentrated higher than $2 \mathrm{~V}$, there appear oscillations of the current in CV. Such oscillations appear also for the samples introduced in alkaline $\mathrm{NaOH}$ solutions, where the modification of the potential takes place continuously from the introduction of the alloy sample, without the possibility of establishing an accurate value of the corrosion potential. In $0.25 \mathrm{M}$ solution a significant increase of the current to $0.400 \mathrm{~V}$ appear, and at $1.00 \mathrm{~V}$ there start the current oscillations which lead to a maximum of about $2.500 \mathrm{~V}$. The polarization curves were drawn out on the potential domain $\mathrm{E}_{\text {cor }} \div 3.500 \mathrm{~V}$, at a $10 \mathrm{mV} / \mathrm{s} \mathrm{rate}$. $\mathrm{E}_{\text {cor }}$ was established by immersing WE in the solution following the potential in open circuit.

The steels dissolution in diluted aqueous solution is electrochemical characterized by the calculation of the corrosion currents corresponding to these systems and by measuring the polarization diagrams on a large potential range when the rate stages determining the dissolution process corresponding to the investigated potential domain are shown.

\section{Conclusions}

In present paper the corrosion of five steel samples having the iron content $97.3 \div 98.90 \%$ through the dissolution in $\mathrm{HNO}_{3}, \mathrm{H}_{2} \mathrm{SO}_{4}$, and $\mathrm{HCl}$ aqueous solutions in the range of $0.25 \div 4 \mathrm{M}$ concentration, by voltammetric method, have been studied. There were revealed electrochemical processes in $\mathrm{CV}$ of the samples dissolved in $\mathrm{HNO}_{3}$ solutions, confirming the complexity of the mechanism of iron dissolution in $\mathrm{HNO}_{3}$ solutions.

To characterize the anodic dissolution of iron there were made WEs from steels taken in the study, to drown out the cyclic voltammograms for the determination of the polarization resistance of Tafel parameters and of the corrosion characteristics.

Out of the polarization curves for the more concentrated solutions (4M) there was defined a pre-passive domain, 
which is not met at the diluted solutions $(0.25 \mathrm{M})$, and at higher potentials there appeared oscillations of the current as well.

For the same steel sample the corrosion potential is higher for the lower acid concentration. Therefore, a possible passivation effect would be stronger for the more concentration acids, which favors the appearance of some protective chemical compounds as oxides, hydroxides or insoluble salts on the contact surface steel sample - corrosion medium.

\section{References}

[1]. Bockris, J.O’M., Kahn, S.U.M., Surface Electrochemistry-A molecular level approach, Plenum Press, New York, 1993, p. 745.

[2]. Du, B., Suni, I.I., J. Appl. Electrochem., 34, 2004, p. 1215.

[3]. Sutiman, D., Cailean, A., C. Chiper, C., Nemtoi, Gh., Rosca, I., Rev. Chim. (Bucharest) 54, 2003, p. 5.

[4]. Sutiman, D., Cretescu, I., Nemtoi, Gh., Rev. Chim.(Bucharest), 50, 1999, p.766.

[5]. Bockris, J.O’M., Comprehansive Treatise of Electrochemistry, 4, Electrochemical materials science, 9, 1981, p.151, Electrodics: Experimental Techniques, Plenum Press, New York and London, 1984, p. 61.

[6]. Crow, D.R., Principles and application of electrochemistry, Chapmann and Hall, London 1988, p. 15.

[7]. Du, B., Suni, I.I., J. Electrochem. Soc., 151 (6), 2004, p. 375.

[8]. Nemtoi, Gh., Annal. West Univ. Timisoara, 12 (3), 2003, p. 609.

[9]. Pourbaix, M., "Electrochemical corrosion of metallic biomaterials", Biomaterials, 5, 1984, p.122.

[10]. Barton, S.C., West, A.C., J. Electrochem. Soc., 148, 2001, p. 381.

[11]. Sato, N., "Toward a More Fundamental Understanding of Corrosion Processes", Corrosion, 45, 1989 , p. 354.

[12]. Molah, M.Y.A., Schenach, R., Parga, J. P., Cocke, D. L., J. Hazard. Mater, B 84, 2001, p. 29.

[13]. Bockris, J.O’M., Koch, D.F.A., J. Phys. Chem., 65, 1961, p. 1948.

[14]. Despic, A.R., Drazic, D.M., Balaksina, J., Gejic. L., Electrochim. Acta, 35, 1990, p. 1747.

[15]. Stern, M., Geory, A.L., J. of Electrochem. Soc., 104, 1957, p. 599.

[16]. Uhling, H., Corrosion and Corrosion Control, John Wiley and Sons Inc., New York, 1971, p. 464.

[17]. Mansfeld, F., The polarization resistance technique for measuring corrosion currents, Advances in Corrosion Science and Technology, 6, Plenum Press, New York, 1976, p. 163.

[18]. Nemțoi, Gh., Secula, M.S., Crețescu, Ig., Petrescu, S., Rev. Roumaine Chim., 52, 2007, p. 655.

[19]. Cecal. A. Stan. V., Z. Phys. Chem. (Leipzig), 263, 1982, p.117.

[20]. Cecal, A., Isotopenpraxis, 20, 1984, p. 259.

[21]. Cecal, A., Ionica, F., Popa, K., Rev. Chim.(Bucharest), 59, 2008, p. 1234. 